\title{
Asymmetries of the Left and Right Temporal Lobes
}

\author{
Asimetría de los Lóbulos Temporales Izquierdo y Derecho \\ Boni, R. C.; "** Prosdócimi, F. C.; "Bonsi, A. B.; ${ }^{* * * *}$ Almeida, T. M. \& ${ }^{* * * *}$ Ribeiro, L. A. M.
}

BONI, R. C.; PROSDóCIMI, F. C.; BONSI, A. B.; ALMEIDA, T. M. \& RIBEIRO, L. A. M. Asymmetries of the left and right temporal lobes. Int. J. Morphol., 25(1):117-120, 2007.

SUMMARY: Anatomical brain asymmetries are subtle and still little studied in humans. Among all the animals, humans have the most asymmetric brains Crow (2004). The language faculty and handedness are localized on the left side. The objective this paper is to verify whether the temporal lobes are anatomically different. Our sample was composed of 40 post mortem adult brains of both sexes, which were investigated at the Human Anatomy Laboratory of the Nove de Julho University Center in São Paulo, Brazil. The brains were fixed in a solution of 5\% paraformaldehyde. Three different measurements were taken using a pachimeter (Mitutoyo) and a goniometer (Carci) on both hemispheres: M1 - the length of the lateral sulcus; M2 - the distance from the lateral sulcus to the inferior margin of the inferior temporal gyrus, and M3 - the angle formed between the lines of the collateral sulcus and the inferior margin of the inferior temporal gyrus. Results were submitted to a statistical analysis (ANOVA) and demonstrated that M1 was larger in the left hemisphere, by contrast with the data obtained for M2 and M3, which were larger in the right hemisphere. The measurements taken showed differences between the right and left temporal lobes.

KEY WORDS: Brain; Asymmetry; Temporal Lobe.

\section{INTRODUCTION}

At the end of the $18^{\text {th }}$ and beginning of the $19^{\text {th }}$ century, a theory of cerebral function was disseminated, which proposed the existence of multiple cerebral organs responsible for specific abilities. The authors of the time nevertheless considered that the two sides of the brain were symmetric and that each organ had its homolog on the other side, which lacked a functional equilibrium (Caldas, 2004).

Around 1861, after studying various cases of left hemisphere lesions and alterations in language, Paul Broca became convinced of the correctness of the studies of Mark Dax, which stated that language ability was localized on the left side of the brain, given that since 1877, it had already been considered that man, among all the other animals, had the most asymmetric brain with the largest quantity of acquired abilities, of which language was the highest, since it distinguished humans from animals. In this way, the concept was established that asymmetry is the defining characteristic of the human brain (Crow, 2004). This concept ran the risk of being lost during the $19^{\text {th }}$ century, but reemerged in the second half of the $20^{\text {th }}$ century due to the anatomical rediscovery of asymmetry by Geschwind \& Levitsky (1968), in a study which compared the two sides of the brain, highlighting above all the asymmetry present in the left hemisphere.

From an anatomical point of view, it has been known since the time of Broca that human brain asymmetries are subtle. It is likely that the most conspicuous asymmetry is that of the temporal lobe, and although researchers have measured it in various different ways, it is still little understood Crow.

Considering these factors, the aim of this study is to verify whether the temporal lobes are anatomically different.

\section{MATERIAL AND METHOD}

Our sample was composed of 40 post mortem adult brains of both sexes, which were investigated at the Human Anatomy Laboratory of the Nove de Julho University Center in São Paulo, Brazil. The brains were fixed in a solution of $5 \%$ paraformaldehyde. Three different measurements were taken using a pachimeter (Mitutoyo) and a goniometer

* Professor Dr. in the Health Department, Human Morphology Division, UNINOVE, Brasil.

** Professor the Health Department, UNINOVE, Brasil.

*** Physiotherapist - Laboratory of Human Anatomy, UNINOVE, Brasil. 


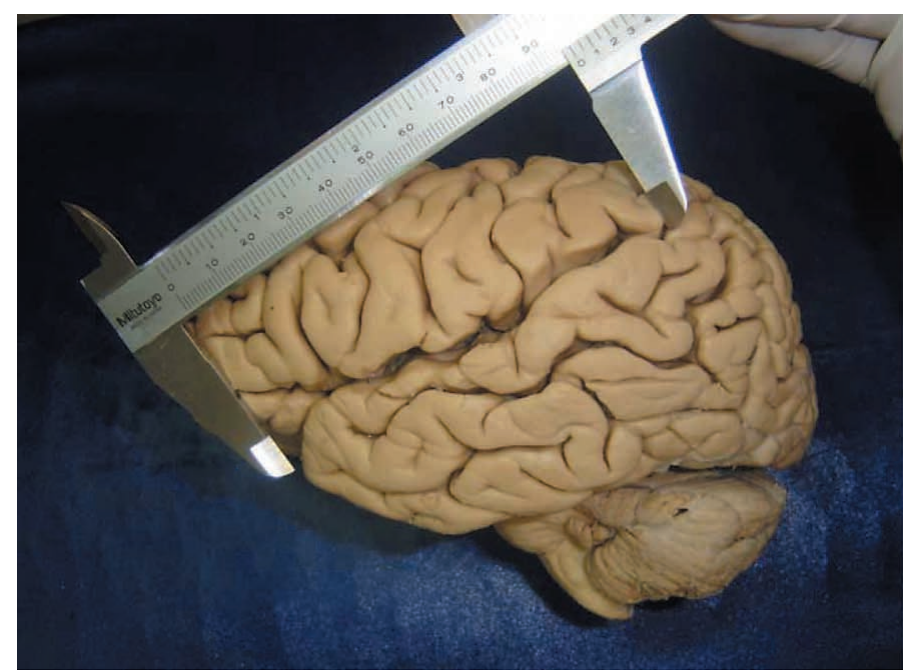

Fig. 1. Length of the lateral sulcus.

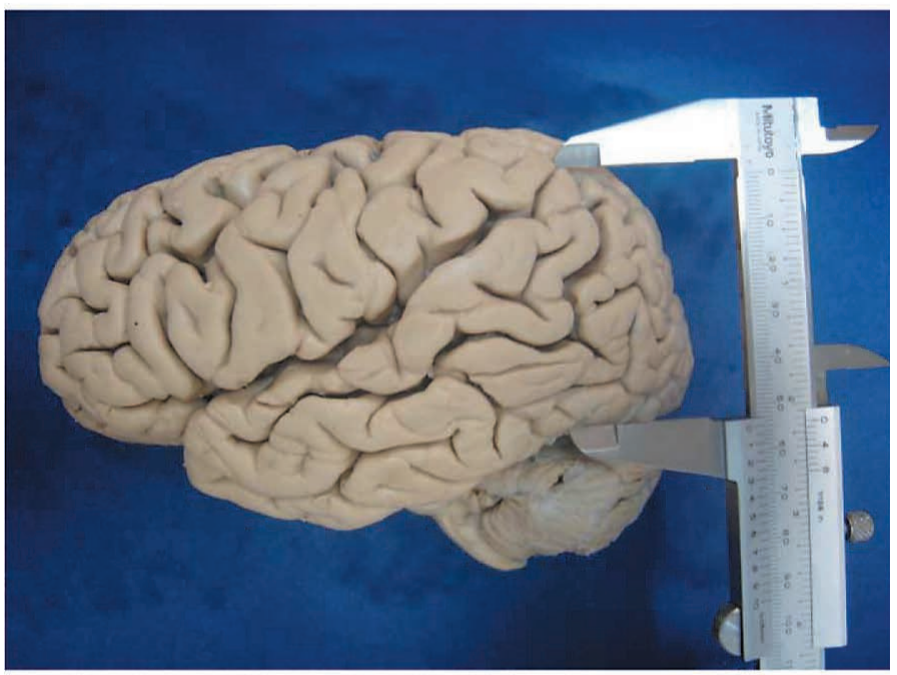

Fig. 2. Distance from the lateral sulcus to the inferior margin of the temporal lobe.

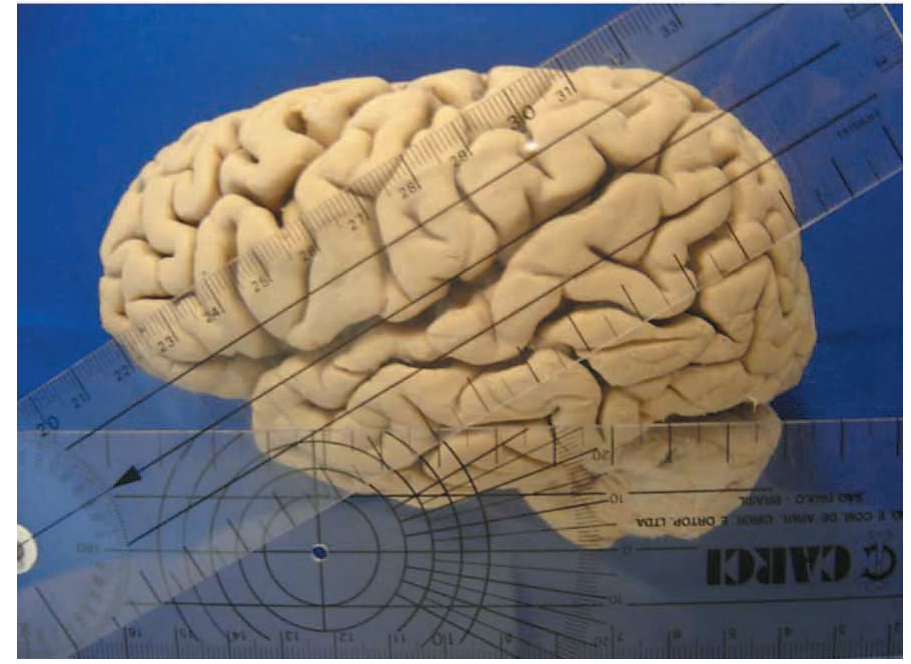

Fig. 3. Angle formed between the lines of the collateral sulcus and the inferior margin of the temporal lobe.
(Carci) on both hemispheres: M1 (Fig. 1), the length of the lateral sulcus; M2 (Fig. 2), the distance from the lateral sulcusto the inferior margin of the inferior temporal gyrus and M3 (Fig. 3) the angle formed between the lines of the collateral sulcus and the inferior margin of the inferior temporal gyrus.

\section{RESULTS}

The aim of this work was study different measures between right and left brain hemispheres, related in previous studies, comparing 40 cadaveric brains, with follow results:

Quantitative Analysis. Results of this measurements in anatomic studies were analysed with foloowing values:

Results of M1 measures (lateral sulcus extension) evidenced that in right hemisphere the medium number was $65,11 \mathrm{~mm}$ and in left hemisphere 79,94 $\mathrm{mm}(16,6 \%$ higher in left hemisphere) (Fig. 4).

Results of M2 measures (distance between lateral sulcus and temporal lobe inferior lobe) evidenced that in right hemisphere the medium number was $46,86 \mathrm{~mm}$ and in left hemisphere $44,28 \mathrm{~mm}(5,95 \%$ higher in right hemisphere) (Fig. 5).

Results of M3 measures (angle between lateral sulcus posterior border and temporal lobe inferior border) evidenced that in right hemisphere the medium number was $30,13^{\circ}$ and in left hemisphere $28,66^{\circ}(5,1 \%$ higher in left hemisphere) (Fig. 6).

Statisc analysis. The statistic analysis ANOVA presented different results between right and left brain hemispheres studied $(\mathrm{p}<0,005)$.

\section{DISCUSSION}

In their study, Geschwind \& Levitsky (1968) cite the fact that the dominance of the human left hemisphere over certain functions is not generally associated with significant structural differences between the two halves of the brain. At the same time, on reinvestigating this problem with a sample consisting of 100 adult human brains, significant asymmetries were found between the right and left hemispheres, with results demonstrating that the temporal plane was $0.9 \mathrm{~cm}$ larger on the left in 
Lateral sulcus extension ( $\mathrm{mm} x$ number of brains)

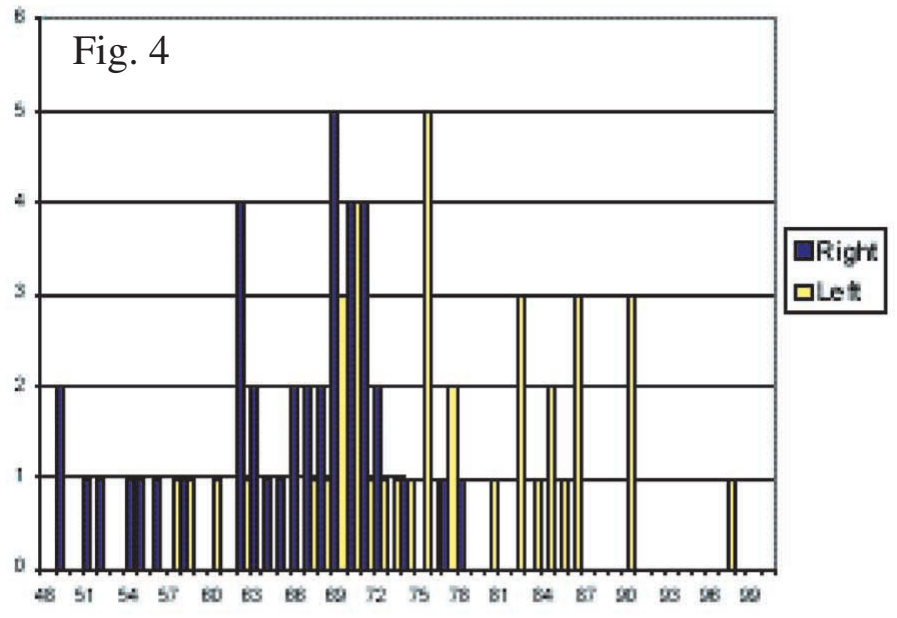

\section{Distance between lateral sulcus and temporal lobe} inferior border ( $\mathrm{mm} \times \mathrm{num}$ ber of brains)

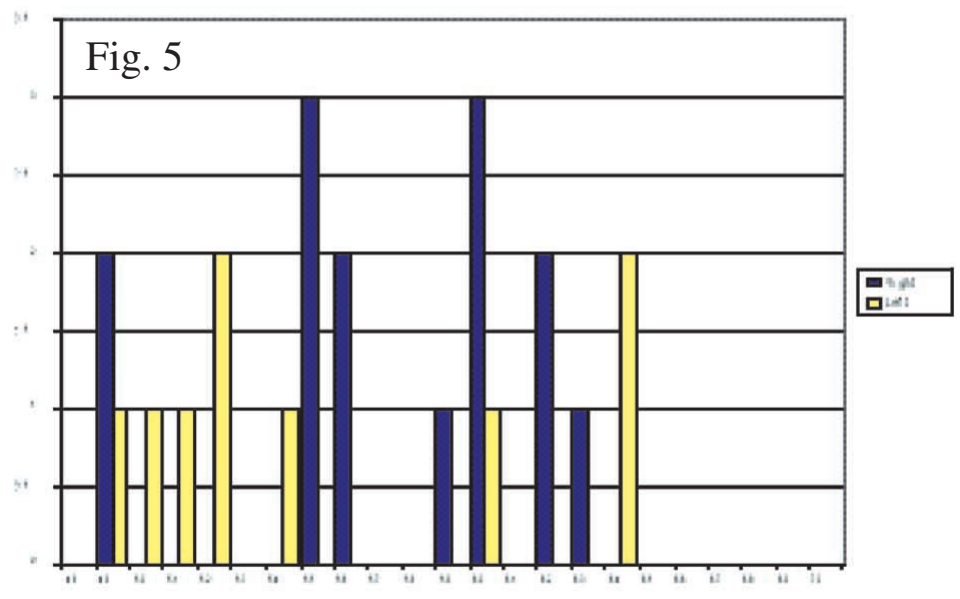

Angle between lateral sulcus posterior border and la teral lobe inferior bo rder (angle $x$ number of bra ins)

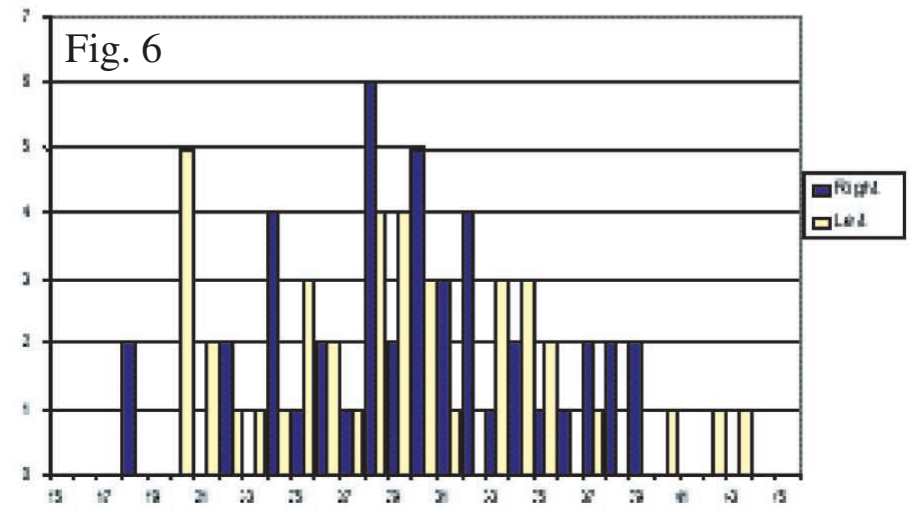

$65 \%$ of the sample, larger on the right in $11 \%$ of the sample and equal in $24 \%$ of the sample, with these measurements compatible with other observations made in past studies that in men the left lateral sulcus larger on average than the right.

The results cited above corroborate the subsequent 1979 work by the same authors, based on lateralization for language in the cerebral hemispheres, for which there is a consensus in the literature, on the basis of the structural asymmetries found. This time, they observed a difference of $7 \mathrm{~cm}$ in the left lateral sulcus compared to the right in an extensive sample.

For Caldas, cerebral dominance is a fundamental characteristic of the process of species evolution, with the left hemisphere and its functions representing the new acquisition of the human species that distinguished it from other species, as proposed in the concept of dominance.

The author realized a work in which he studied the anatomical asymmetries between the cerebral hemispheres, drawing attention to the asymmetry observed in the temporal plane, and also highlighting that the same is difficult to study in recently autopsied cadavers due to low density, thus suggesting that the same can only be analyzed with greater rigor after fixation in formol or in another way.

Cerebral asymmetries are similar both in modern and in fossil humans. Most frequent among these is the lateral sulcus, which may be found not only in humans, but also in monkeys, chimpanzees and orangutans, albeit in less conspicuous form in these latter animals (Yemi-Komshian \& Benson, 1976).

Considered by Rubens et al. (1976) as the most prevalent and consistent structural difference found in adult and fetal brains, the left asymmetry of the lateral sulcus may perhaps be justified by the important function of language in the same hemisphere. While Witelson \& Kigar (1992) suggest that anatomical asymmetry is associated with functional asymmetry, given that the majority of men are right-handed.

This study concludes, on the basis of the measurements made, that there are differences between the right and left temporal lobes. 
It is important to highlight here that the hemispheres of the brain are not identical organs, either from an anatomical or from a functional view point, and we suggest that new studies are undertaken so that we can become familiar with and understand asymmetry in its essence.

BONI, R. C.; PROSDÓCIMI, F. C.; BONSI, A. B.; ALMEIDA, T. M. \& RIBEIRO, L. A. M. Asimetría de los lóbulos temporales izquierdo y derecho. Int. J. Morphol., 25(1):117-120, 2007.

RESUMEN: Las asimetrías anatómicas del cerebro humano son sutiles y aún poco estudiadas. Entre todos los animales, el Hombre es el que presenta el cerebro más asimétrico (Crow, 2004). En el lado izquierdo del cerebro se localiza la facultad del lenguaje, como también de la lateralidad manual. El objetivo del trabajo fue verificar si los lóbulos temporales son anatómicamente diferentes. La muestra estuvo compuesta de 40 encéfalos adultos, post mortem, de ambos sexos, del Laboratorio de Anatomía del Centro Universitario Nove de Julho, en São Paulo, SP, Brasil. Los encéfalos fueron fijados en solución de formalina al 5\%. Fueron realizadas 3 medidas diferentes utilizando un pié de metro Mitutoyo y goniómetro (Carci), en ambos hemisferios: medida M1, largo del surco lateral; medida M2 distancia del surco lateral hasta el margen inferior del giro temporal inferior y la medida M3 el ángulo formado entre las líneas del surco colateral y margen inferior del giro temporal inferior. Los resultados se sometieron a análisis estadístico y mostraron que M1 era mayor en el hemisferio izquierdo, en contraposición a los datos obtenidos en M2 y M3, que fueron mayores en el hemisferio derecho. Las medidas realizadas presentaron diferencias entre los lóbulos temporales derecho e izquierdo.

PALABRAS CLAVE: Cerebro, Asimetría; Lóbulo temporal.

\section{REFERENCES}

Caldas, C . A. O conceito de dominância cerebral revisitado. Re (habilitar)-ESSA 0:17-33, 2004.

Crow, T. J. Assimetria cerebral e lateralização da linguagem: déficits nucleares na esquizofrenia como indicadores de predisposição genética. Psiquiatria RS, 26(2):122-34, 2004.

Geschwind, N. \& Levitsky, W. Human brain: left-right asymmetry in temporal speech region. Science, 161:1867, 1968.

Rubens, A.; Mahwold, M. \& Hutton, J. Asymmetry of the lateral Sylvian fissures in man. Neurology, 26:620-4, 1976.

Witelson, S. \& Kigar, D. Sylvian fissure morphology and asymmetry in men and women: bilateral differences in relation to handedness in men. J. Comp. Neurol., 323:326-40, 1992.

Yemi-Komshian, G. \& Benson, D. Anatomical study of cerebral asymmetry in the temporal lobe of humans, chimpanzees, and rhesus monkeys. Science, 192:387-9, 1976.
Correspondence to:

Prof. Dr. Rosana Cristina Boni

Rua Tucuna 481, Apt. 204

Bairro Perdizes

CEP 05021010

São Paulo SP

BRASIL

Email: roboni@uninove.br

Received: 09-10-2006

Accepted: 23-12-2006 